\title{
Heats of Polymerization. A Summary of Published Values and Their Relation to Structure
}

\author{
By Donald E. Roberts
}

\begin{abstract}
This paper contains a table showing values of heats of polymerization assembled from a survey of the literature. There are 42 substituted vinyl compounds arranged as follows: vinyl alkyls, vinyl aryls, other vinyls, vinyl acids and esters, dienes and copolymers. Values reported by different authors are given for each compound, with corresponding states of monomers and ploymers and a notation on the methods used in obtaining the values. A second table gives structural formulas of monomers.

Some values of heats of polymerization to hypothetical polymers having no steric hindrance are calculated from published values of heats of formation of hydrocarbons, making certain assumptions regarding branch groups. The method of calculation is explained. Heat of polymerization is arbitrarily assigned to four energy effects: (1) the reaction $\mathrm{C}=\mathrm{C} \longrightarrow-\mathrm{C}-\mathrm{C}-;(2)$ the effect of side groups on bond energies when there is no interaction between the groups; (3) the effect of steric hindrance between side groups; and (4) the "end effect" arising from the nearness of the double bond to the end of the monomer molecule.

Values of heats of polymerization are compared, and their relation to structure is examined, with particular emphasis on the effect of steric hindrance. Etyhlene has the highest and alpha-methylstyrene the lowest heat of polymerization; isobutene and the methacrylates also are low. Disubstitution on the same vinyl carbon is a frequent cause of steric interference, with consequent reduction in heat of polymerization. Large branched substituents may cause steric interference. The substitution of chlorine on the aromatic ring of styrene has little effect on heat of polymerization. Steric interference may prevent polymerization above the dimer. The heat of copolymerization of butadiene and styrene lies between the values for the separate monomers. Heat of copolymerization of other monomer pairs may be higher or lower than the value for the separate components. Heat of polymerization depends somewhat on the ratio of 1,2- and 1,4-addition, and on the amount of crystallinity of the polymers.
\end{abstract}

\section{Introduction}

Values of the heats of polymerization of various materials are recorded in many journal articles, but there is no recent systematic compilation and comparison of these values. Flory [1] ${ }^{1}$ calculated a number of values in 1937 before there were many experimental observations available, and Roth and Rist-Schumacher [2] published in 1942 a summary of values almost entirely obtained from

\footnotetext{
1 Figures in brackets indicate the literature references at the end of this
} paper.
German sources. Since then a large number of experimental observations have been made, and many interesting comparisons are now possible. This paper has been written to collect the scattered data and list them in a convenient form for reference so that useful values of heats of polymerization can readily be obtained without extensive searching. A second purpose is to permit comparison of the data for different compounds, so that systematic trends and anomalies can be recognized. The discussion that follows calls attention to some of the relations between the 
heats of polymerization and the structures of the monomers and polymers. The reader may wish to make further comparisons of the types illustrated.

\section{Description and Use of Tables}

The table of values of heats of polymerization (table 1) is arranged for convenience according to substituent groups as follows: vinyl alkyls, vinyl aryls, other vinyls, and vinyl acids and esters; these are followed by dienes and copolymers. Within each class, the compounds are arranged according to increasing size and molecular weight of the monomer. The values reported by the several authors are arranged chronologically for each compound.

TABLE 1. Heats of polymerization

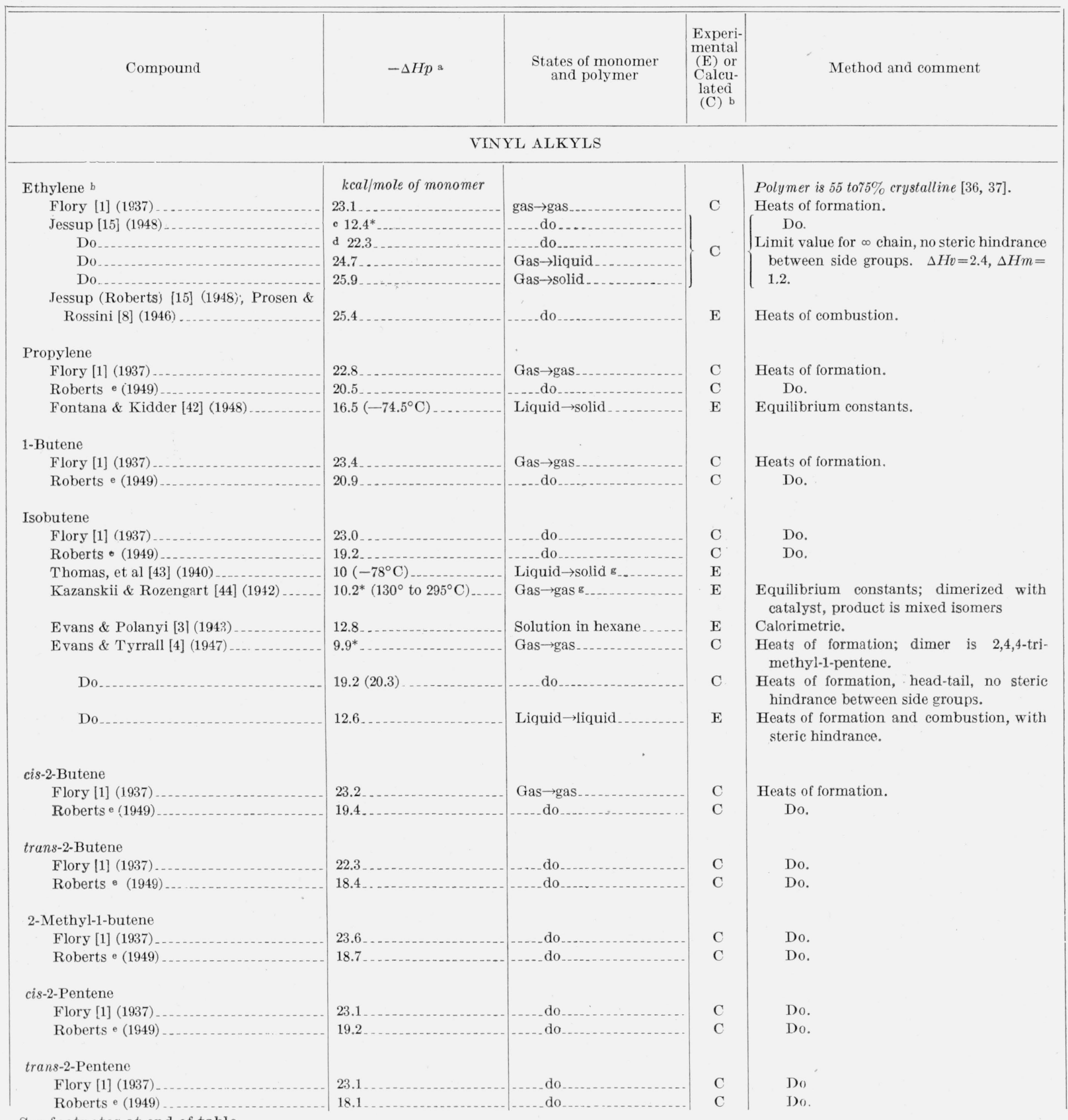

See footnotes at end of table. 
TABLE 1. Heats of polymerization-Continued



See footnotes at end of table. 
TABLE 1. Heats of polymerization-Continued

\begin{tabular}{|c|c|c|c|c|}
\hline Compound & $-\Delta H p$ a & $\begin{array}{l}\text { States of monomer } \\
\text { and polymer }\end{array}$ & $\begin{array}{l}\text { Experi- } \\
\text { mental } \\
\text { (E) or } \\
\text { Calcu- } \\
\text { lated } \\
\text { (C) b }\end{array}$ & Method and comment \\
\hline \multicolumn{5}{|c|}{ OTHER VINYLS-Continued } \\
\hline $\begin{array}{l}\text { Vinylidene chloride } \mathrm{h} \\
\text { Tong \& Kenyon [41] (1947) } \\
\text { Vinyl butyl ether b } \\
\quad \text { Shostakovskii \& Bogdanov [52] (1942) . }\end{array}$ & $\begin{array}{l}\text { kcal/mole of monomer } \\
14.4\left(76.8^{\circ} \mathrm{C}\right) \\
14.4\left(40^{\circ} \text { to } 60^{\circ} \mathrm{C}\right)\end{array}$ & $\begin{array}{l}\text { Liquid } \rightarrow \text { solid } \ldots \ldots \\
\text { Liquid } \rightarrow \text { liquid } \mathrm{g}_{\ldots} \ldots \ldots\end{array}$ & $\mathrm{E}$ & $\begin{array}{l}\text { Polymer is largely crystalline }[39,40] \text {. } \\
\text { Isothermal calorimeter; extrapolated to } \\
\quad \text { zero catalyst. } \\
\text { Polymerized with alcoholic } \mathrm{FeCl}_{3} \text {. }\end{array}$ \\
\hline \multicolumn{5}{|c|}{ VINYL ACIDS AND ESTERS } \\
\hline $\begin{array}{l}\text { Acrylic acid } \\
\text { Staudinger \& Schläpfer [51] (1939) } \\
\text { Evans \& Tyrrall [4] (1947) } \\
\text { Methacrylic acid } \\
\text { Evans \& Tyrrall [4] (1947) } \\
\text { Methyl acrylate } \\
\text { Evans \& Tyrrall [4] (1947) } \\
\text { Tong \& Kenyon [41] (1947) } \\
\text { Methyl methacrylate } \\
\text { Iwai [53] (1946) } \\
\text { Tong \& Kenyon [54, 55] (1945-46) } \\
\text { Tong \& Kenyon [54] (1945) } \\
\quad \text { Do . } \\
\text { Kunst \& Magat [56] (1947) } \\
\text { Evans \& Tyrall [4] (1947) } \\
\quad \text { Do } \\
\text { Tenzyl methacrylate } \\
\text { Tong \& Kenyon [55] (1946) } \\
\text { Tong \& Kenyon [55] (1946) } \\
\text { Ethyl methacrylate } \\
\text { Iwai [53] (1946) }\end{array}$ & $\begin{array}{l}16.3 \\
13.0\left(76.8^{\circ} \text { to } 110^{\circ} \mathrm{C}\right) \\
13.1\left(76.8^{\circ} \mathrm{C}\right) \\
13.6\left(76.8^{\circ} \mathrm{C}\right) \\
10 \text { to } 13 \\
12.9 \\
14.1 \\
13.5\left(76.8^{\circ} \mathrm{C}\right) \\
12.3\left(76.8^{\circ} \mathrm{C}\right) \\
12.2\left(76.8^{\circ} \mathrm{C}\right) \\
13.4\left(76.8^{\circ} \mathrm{C}\right)\end{array}$ & $\begin{array}{l}\text { Solution }(51 \%) \text { in } \mathrm{CCl}_{4} \\
\text { Solution } 26 \text { to } 32 \% \mathrm{H}_{2} \mathrm{O} \text {, } \\
26 \text { to } 32 \% \mathrm{MeOH} \text {. } \\
\begin{array}{l}\text { Emulsion } 25 \mathrm{ml} \text { in } \\
\text { ml } \mathrm{H}_{2} \mathrm{O} \text {. } \\
\text { Gas } \rightarrow \text { gas }_{\text {L }}\end{array} \\
\text { Liquid } \rightarrow \text { solid g } \\
\text { do }\end{array}$ & $\begin{array}{l}\mathrm{E} \\
\mathrm{E} \\
\mathrm{E} \\
\mathrm{E} \\
\mathrm{E} \\
\mathrm{E} \\
\mathrm{C}\end{array}$ & $\begin{array}{l}\text { Heats of combustion. } \\
\text { Calorimetric. } \\
\text { Do. } \\
\text { Do. } \\
\text { Isothermal calorimeter; not corrected for } \\
\text { unreacted monomer; } 0.01 \% \text { benzoyl } \\
\text { peroxide. } \\
\text { Heats of combustion. } \\
\text { Isothermal calorimeter. } \\
\text { Do. } \\
\text { Isothermal calorimeter; polymer insoluble } \\
\text { in MeOH-H }{ }_{2} \mathrm{O} \text {. } \\
\text { Calorimetric. } \\
\text { Estimated from isobutene, head-tail, no } \\
\text { steric hindrance between side groups. } \\
\text { Heats of combustion. } \\
\text { Isothermal calorimeter. } \\
\quad \text { Do. } \\
\text { Do. } \\
\text { Do }\end{array}$ \\
\hline & & IENES & & \\
\hline $\begin{array}{l}\text { 1,3-Butadiene } \\
\text { Lebedev, et al [31] (1935) } \\
\text { Do } \\
\text { Flory [1] (1937) } \\
\text { Roberts e (1949) } \\
\text { Flory [1] (1937) } \\
\text { Roberts e (1949) } \\
\text { Roberts \& Jessup [57] (1948); Prosen \& } \\
\quad \text { Rossini [5] (1945) } \\
\quad \text { Do } \\
\text { Baur \& Frater [5.5] (1941) } \\
\text { 1,4-Pentadiene } \\
\text { Flory [1] (1937) } \\
\text { Roberts e (1949; }\end{array}$ & $\begin{array}{l}18.1 \text { to } 38.4 \\
12.2 \text { to } 32.5 \\
19.9 \\
17.4 \\
20.4 \\
18.7 \\
8.7^{*}\left(149^{\circ} \text { to } 185^{\circ} \mathrm{C}\right)\end{array}$ & $\begin{array}{l}\text { Gas } \rightarrow \text { solid } \\
\text { Liquid } \rightarrow \text { solid } \\
\text { Gas } \rightarrow \text { gas } \\
\text { Gas } \rightarrow \text { do solid } \\
\text { Liquid } \rightarrow \text { solid }\end{array}$ & $\begin{array}{l}\text { E } \\
\text { C } \\
\text { C } \\
\text { C } \\
\text { C }\end{array}$ & $\begin{array}{l}\text { Heats of combustion; several polymers, } \\
\text { formed in different ways. } \\
\text { Heats of formation, 1,2-polymerization. } \\
\text { Heats of formation, 1,2-polymerization. } \\
\text { Heats of formation, 1,4-polymerization. } \\
\text { Heats of formation, 1,4-polymerization. } \\
\text { Heats of combustion. } \\
\quad \text { Do. } \\
\text { Equilibrium constant, dissociation at con- } \\
\text { stant volume. Cyclic dimer. } \\
\text { Heats of formation, 1,2-polymerization. } \\
\text { Heats of formation, 1,2-polymerization. }\end{array}$ \\
\hline
\end{tabular}


TABLE 1. Heats of polymerization-Continued

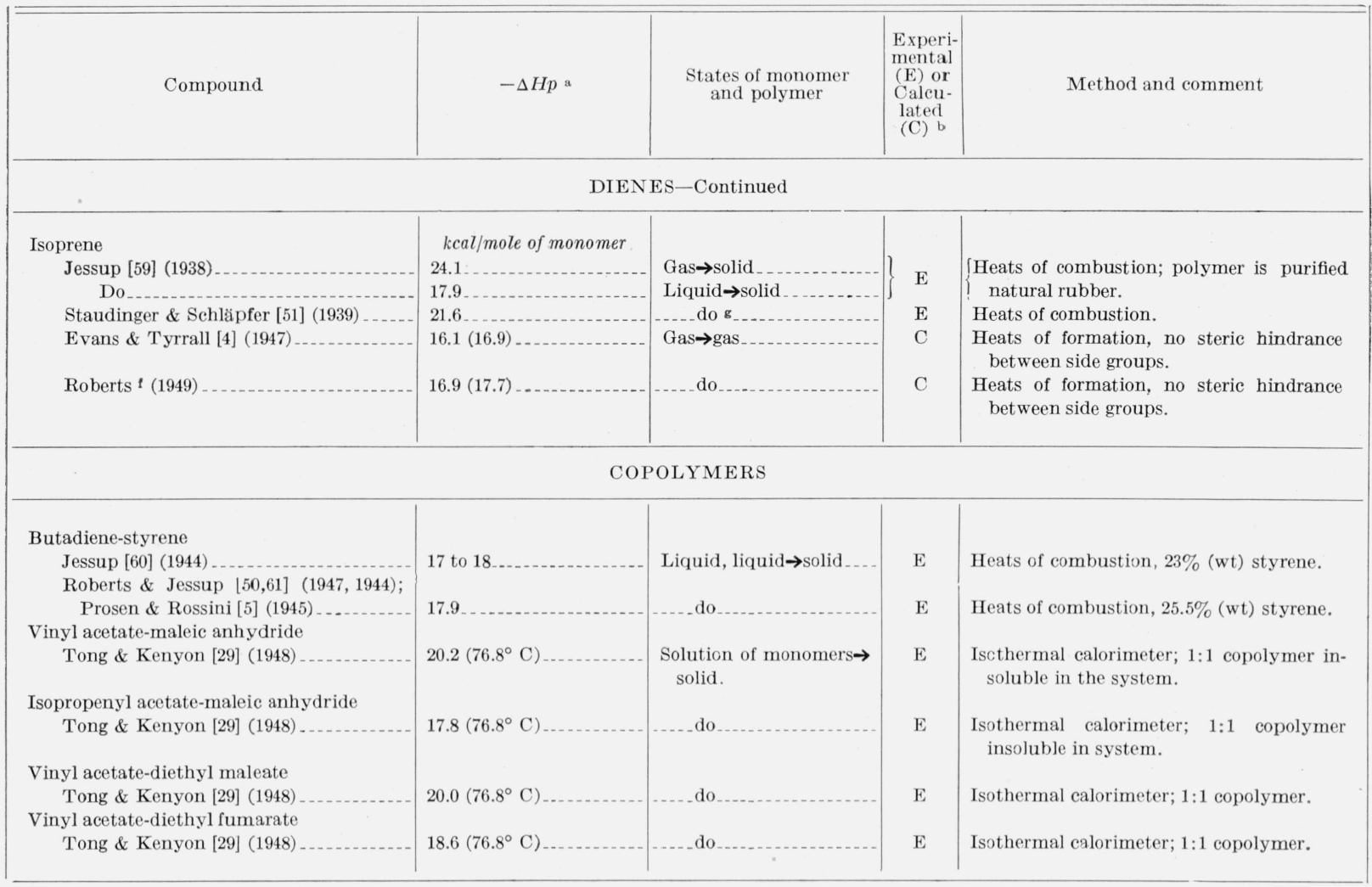

a At or near $25^{\circ} \mathrm{C}$ unless otherwise indicated.

b The calculated values (except those for ethylene and dimerization if isobutene) are not the actual heats of polymerization which would be obtained experimentally, but apply only to hypothetical ploymers that are free from steric interference between substituent groups attached to the polymer chain.

${ }^{*}$ denotes heat of dimerization.

d Recalculation of Flory's values by the author was done in the same manner and gives this same value.

e Recalculated by the author following Flory [1] (see Section III).

f Reference [62] gives a value for the heat of formation of isoprene, supposed to be the "best value" to date. It was obtained by applying certain corrections to the data of Jessup [59] (which was used unchanged by Evans and Tyrrall), and combining this result with calculations by Prosen and Rossini. Using this value for isoprene, calculations like those of Evans and Tyrrall give the values shown for $-\Delta H p$.

g Probable states.

h See comments in last column.

A table of structural formulas (table 2) is included so that the reader can readily compare the structural features of the polymers. The arrangement of this table is the same as that of table 1 . The monomers are shown with the vinyl or diolefin group as the principal portion with sub- stituent groups to the side. The polymer chain would be formed by joining these vinyl or diolefin groups. Since the diagrams in table 2 represent only one view of the molecule, they do not show the zig-zag nature of the polymer chain, which is shown here in idealized form:
Polybutadiene (cis-1,4-polymerization)<smiles>CC/C=C\CC1(C)C=CC(/C=C\CC)(CC)C1</smiles> 
TABLE 2. Formulas and molecular weights

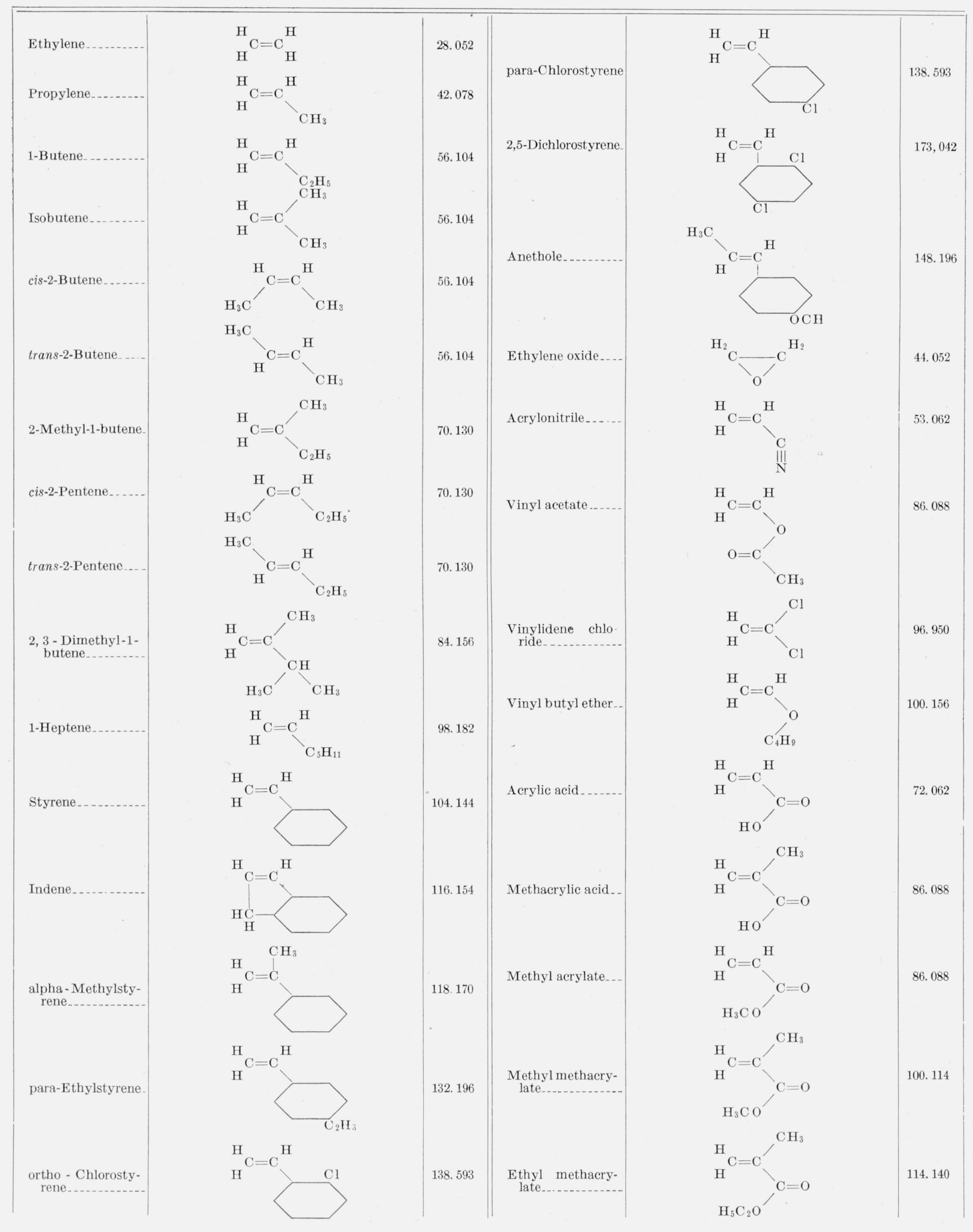


TABLE 2. Formulas and molecular weights-Continued

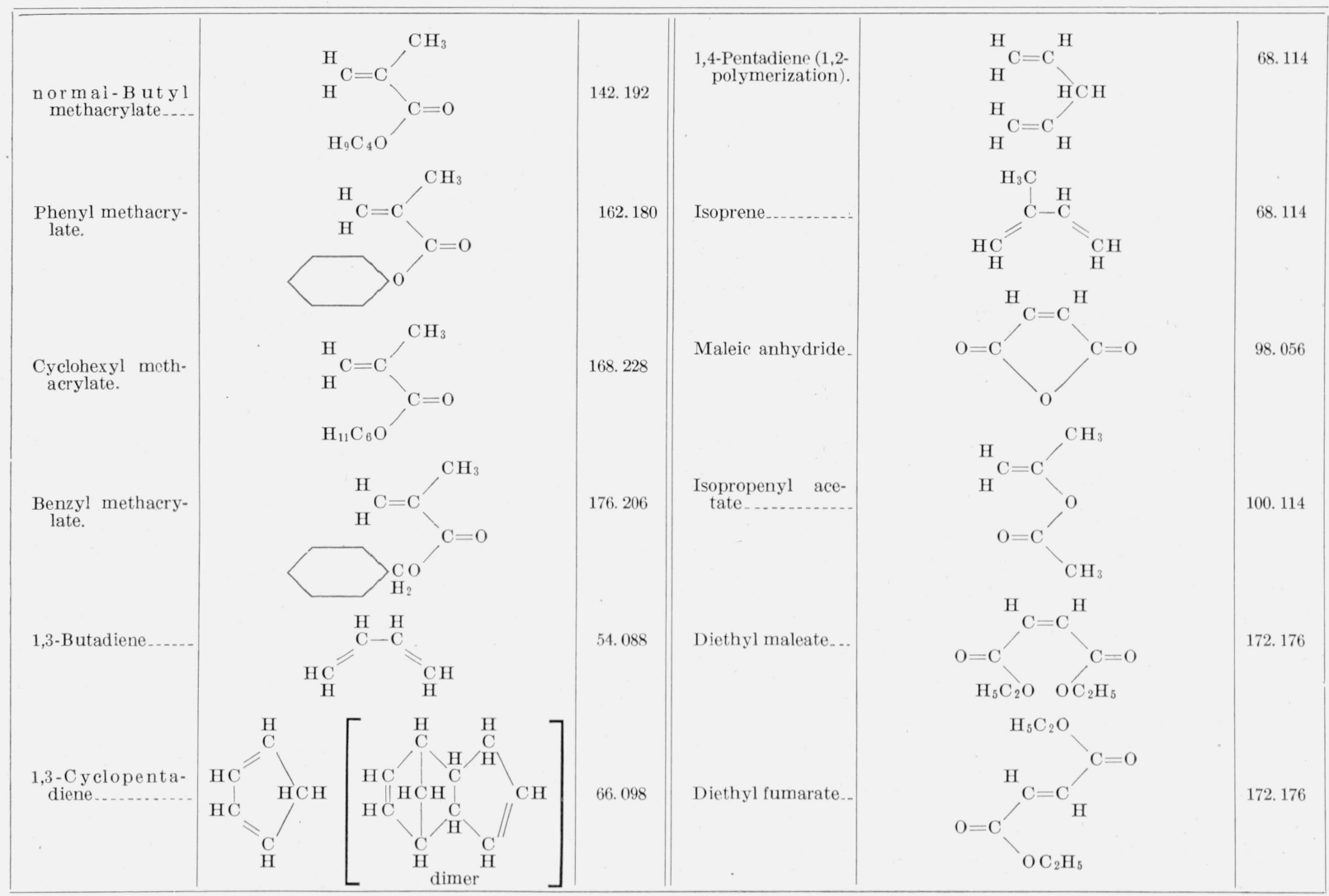

Some values of heat of polymerization that can be found in the literature have not been included in the table for one of three reasons: (1) the compounds are not closely related to those listed here (e. g., tricyano compounds) and involve a different type of reaction; condensation reactions also are excluded; (2) the values reported appear to be in serious error, e. g., because of oxidation of the material; (3) values have been superseded by later values by the same authors. Early values reported by other authors have been included for completeness, although some of these values may be regarded as obsolete. Heats of polymerization can be calculated not only from heats of combustion and formation, but also from activation energies and equilibrium constants. There are many data in the literature other than those listed in this paper, from which heats of polymerization could be calculated if desired, although in some cases the uncertainty of such values will be large.

The states of monomer and polymer and the corresponding values of heats of polymerization given in table 1 are those reported by the several authors, and no corrections have been applied. The values have been rounded to the nearest 0.1 kcal in some cases, since uncertainties in general may amount to the order of $0.5 \mathrm{kcal}$. Values of heat capacities, and of heats of fusion, vaporization, and solution are known only for a few monomers and polymers, so it is not often possible to convert values of heats of polymerization to correspond to temperatures and states other than those in which the measurements were made. It can sometimes be assumed [3,4] that the heats of fusion, vaporization and solution for the polymer are not very different from those for the monomer because of the chemical similarity with the monomer.

In making comparisons of heats of polymerization, values for equivalent states should be used, otherwise the included heats of vaporization, fusion, and solution may result in misleading values, especially if these heats are unusually large, as in styrene [5]. For polymers that are noncrystalline or have a second-order transition with no heat of fusion, as in polystyrene [6], the solid 
state is equivalent to the liquid state for purposes of comparison. Strictly, comparisons of heats of polymerization should be made only when the monomers and polymers are all referred to the same state. In converting values of heats of polymerization to other states, heats of vaporization, fusion, and solution should be used which are for the same temperature as that which applies to the heat of polymerization. The possibility of dependence of heat of solution upon concentration should also be considered.

\section{Recalculation of Flory's Values}

The author of this paper has recalculated the values given by Flory [1] for heats of ploymerization to hypothetical head-to-tail polymers having no steric hindrance between branch groups attached to the polymer chain. The method of calculation was essentially the same as Flory's except that a later expression for heats of formation of hydrocarbons [7] was used in calculating heats of formation of polymers, and the heats of formation of the monomers were obtained directly from [8], or for 1,4-pentadiene from [9], instead of calculating them. The estimated corrections for branching in the polymer were obtained by comparing the heats of formation of the octanes [7] (see also [4]). These were chosen from the available data as being more likely than shorter molecules to give the best approximations.

The recalculated values are 1 to 5 kcal lower than those given by Flory, varying between 18 and $21 \mathrm{kcal} / \mathrm{mole}$ of monomer; there are also greater differences among the recalculated values. The calculated values for the diolefins are not appreciably lower than those for the monolefins. Hypothetical polymers without steric hindrance having double-branch structures have lower heats of polymerization (18.1 to $19.4 \mathrm{kcal} / \mathrm{mole}$ of monomer) than do those with single-branch structures (20.5 to 20.9); polymers with trans structure have heats of polymerization about 1 kcal less than those with cis structure. The calculated value for 1,2-polymerization of 1,3butadiene (17.4) is much lower than that for 1,4-pentadiene (20.7). The hypothetical value for polymerization of styrene $(19 \mathrm{kcal})$, obtained by use of the calculations of Kharasch [10] as was done by Flory, falls about 1.5 keal lower than that for the single-branch structures.
The above relations are due partly to the assumption of certain values for branch corrections and apply to polymers having no steric interference between side groups. The calculations were performed as follows:

The expression for heat of formation per mole of a long normal saturated hydrocarbon, $\mathrm{C}_{n} \mathrm{H}_{2 n+2}$ $(n>5$,gas $)[7]$ is:

$$
\begin{gathered}
\Delta H f_{298}^{\circ}=-10.408-4.926 n \mathrm{kcal} / \mathrm{mole}, \\
\quad=-4.926 n \text { as } n \text { approaches } \infty .
\end{gathered}
$$

If the chain is sufficiently long, any part of it will have a heat of formation proportional to the length of that part. The heat of formation of a structural unit of the hypothetical polymer is then $\Delta H f^{\circ}$ (unit) $=-4.926 n+\Delta_{b} \mathrm{kcal} /$ unit where $\Delta_{b}$ is the correction for the bond effect of branches on the unit. The heat of polymerization is obtained by taking the difference in heats of formation in the gas state of the polymer unit and the monomer, $\Delta H f^{\circ}(m)[8,9]: \Delta H p^{\circ}=-4.926 n$ $+\Delta_{b}-\Delta H f^{\circ}(m) \mathrm{kcal} / \mathrm{mole}$ of monomer. The unsaturated group at the end of the polymer chain is neglected. Since the above calculations apply to saturated polymers, a correction must be applied for diolefins in which an unsaturated group remains. The same values of heats of hydrogenation may be used as in Flory's calculations: +29.95 kcal for $-\mathrm{HC}=\mathrm{CH}_{2}$ and +27.80 kcal for $-\mathrm{HC}=$ $\mathrm{CH}-$. These values were obtained as the mean of those given in [11,12] for mono- and 1,2-disubstituted ethylenes and reduced to $298^{\circ} \mathrm{C}$ by the correction $-0.25 \mathrm{kcal}$.

In calculating corrections for branching, the heat of formation [7] of $n$-octane was compared with that of 4-methylheptane for the correction where there is a single branch per polymer unit, 3,3-dimethylhexane where there are two branches on one of the carbons of the polymer unit, and 3,4-dimethylhexane where there are adjacent single branches in the polymer unit. The following assumptions were made in applying the branch corrections for hypothetical polymers:

1. Length of a normal alkyl substituent makes little difference in bond effect. (This is supported by data of Kistiakowsky and coworkers [12] on heats of hydrogenation.)

2. Branches in the octanes mentioned are far enough removed from the end carbon atoms to 
avoid end effects, so that a suitable value for the branch effect is obtained by comparing these octanes.

3. The application of branch corrections to the hypothetical polymer unit is appropriate when those corrections were obtained from correspondingly branched octanes. This neglects the small bond effect of having substituents on nearby $\mathrm{C}$ atoms of the polymer chain, which are not present in the octanes. Although certain objections can be raised to the use of these branching corrections, it is felt that they afford a better approximation than those available at the time of Flory's calculations, and they were obtained from the best data available at the present time.

\section{Comparison of Values and Steric Effects}

The heat of polymerization of vinyl compounds can be arbitrarily assigned to four energy effects, which are not entirely separable, the second and third being negative with respect to the first and fourth. These energy effects are: (1) the reaction $\underset{\mathrm{C}}{\mathrm{C}=\mathrm{C}} \longrightarrow \mathrm{C}-\mathrm{C}-\mathrm{C}-\mathrm{C}-$; (2) the effect of side groups on bond energies when such side groups are so spaced that there is no interaction between them; (3) the effect of steric hindrance between side groups attached to the polymer chain; (4) the "end effect" arising from the nearness of the double bond to the end of the monomer molecule [13].

The first and fourth effects are represented by the polymerization of ethylene, whose polymer has no side groups and therefore no bond effect nor steric hindrance from such groups. The second effect arises from the fact that the bonds to the substituents and the chain bonds in the monomer have different effects on each other from those they exert in the polymer. The value of the third effect can be obtained by the difference between the calculated values of heats of polymerization, which include effects (1), (2), and (4), for the hypothetical polymers, and the experimental values, which include all effects. Both calculated and experimental values are available in only a few cases; isobutene may be used as an example. The difference between 19.2 calculated and 12.8 observed is $-6.4 \mathrm{kcal} /$ mole of monomer, attributable to steric hindrance between side groups.
The end effect will be different for each monomer and can generally be neglected in polymers. The value of this effect is given by the deviations from linearity with number of carbon atoms of the heats of formation of the lower members of the homologous series and is known at present for only a. few monomers, as follows [14]:

$\begin{array}{lc}\text { Ethylene } & +2.76 \mathrm{kcal}, \\ \text { Propylene } & 0.7, \\ \text { 1-Butene } & 0.39, \\ \text { 1-Heptene } & 0.00 .\end{array}$

For the others, it is estimated to be of the order of $0.5 \mathrm{kcal}$ or less. This effect will make a small difference in the values obtained in comparison of heats of polymerization, depending on the difference in the end effects of the monomers to be compared. The true value of effect (1) above is 19.59 kcal, obtained by deducting the end effect in ethylene from the value $22.35 \mathrm{kcal}$ [15].

Substituent groups of larger sizes may cause greater amounts of steric interference, resulting in lower experimental heats of polymerization. Length of the $n$-alkyl substituents makes little difference, although branched substituents may cause steric hindrance [12]. The substitution of chlorine on the aromatic ring of styrene has little effect on the heat of polymerization, since the substituent is well removed from the polymerizing bonds and is not likely to interfere with other branch groups. In ethylene whose polymer has no steric hindrance between side groups, the experimental and calculated values of heat of polymerization agree within experimental error (the calculated values for ethylene were derived from experimental data on hydrocarbons), whereas isobutene, alpha-methylstyrene, and the methacrylates have values of heat of polymerization about two-thirds of what would be expected if there were no steric hindrance between side groups. Ethylene has the highest and alphamethylstyrene the lowest heat of polymerization among the compounds listed.

A frequent cause of steric interference between side groups is the presence of two substituents on the same vinyl carbon atom, especially if one or more of the substituents is a methyl group. This 
can be seen by comparing the experimental values of heat of polymerization for styrene $(16.7 \mathrm{kcal})$ and alpha-methylstyrene (8.8 to $10.1 \mathrm{kcal})$. If the latter values are increased by an allowance of $2.2 \mathrm{kcal}$ for the bond effect of the methyl group, they become 11.0 to $12.3 \mathrm{kcal}$, respectively. (The value $2.2 \mathrm{kcal}$ is obtained by taking the difference between the calculated values for 1-butene and 2-methyl-1-butene in table 1.) Effect (4) above cancels in this comparison. A substituent phenyl group may be able to rotate so that its plane is perpendicular to the direction of the polymer chain thus making the steric interference less than might be expected [3]. Another example of the effect of disubstitution can be seen by comparing methyl acrylate $(18.7 \mathrm{kcal})$ and methyl methacrylate $(13.0+2.2=15.2 \mathrm{kcal})$.

Steric hindrance becomes so great in some molecules that polymerization becomes impossible, although in some cases a dimer may be formed $[3,16]$. There is generally no steric interference between side groups in dimers, but it becomes noticeable in the trimers and higher polymers in those polymers that show that property [4]. For actual polymers, in the absence of steric hindrance between side groups, heat of polymerization per mole of monomer should increase as the polymer chain becomes longer, because of the factor $(1-1 / n)$, which takes account of the fact that there is one less bond reacting than there are monomer units, as shown in Jessup's calculations for ethylene [15]. (The expression for heat of polymerization of ethylene $[13,14,15]$ may be written $\Delta H p^{\circ}=-19.59(1-1 / n)-\delta$, where $\delta$ is the end effect in ethylene, $2.76 \mathrm{kcal}$.) If steric hindrance occurs in the polymer, its effect should increase rapidly at first as more units are added to the chain, and after the first three units the heat of polymerization per monomer unit should either increase more slowly or decrease, and the steric energy per unit added should approach a constant value as the chain lengthens. The data for alpha-methylstyrene [17] show some of these effects; here the heat of polymerization per mole of monomer decreases as the molecular weight increases

Ethylene oxide appears to be a somewhat different monomer from the others listed. The reaction, which differs from vinyl polymerization in being a stepwise addition process rather than a free radical mechanism $[18,19,20]$ involves the net difference of the breaking of one $\mathrm{C}-\mathrm{O}$ bond and the forming of another $\mathrm{C}-\mathrm{O}$ bond in the chain:

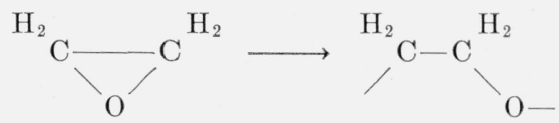

This simple $\mathrm{C}-\mathrm{O}$ bond rearrangement in itself cannot account for the heat of polymerization. The chain is terminated by $-\mathrm{OH}$ groups: $\mathrm{HO}-\mathrm{H}_{2} \mathrm{C}$ $\left(\mathrm{H}_{2} \mathrm{C}-\mathrm{O}-\mathrm{CH}_{2}\right)_{n} \mathrm{CH}_{2}-\mathrm{OH}$, but if the average molecular weight is large, the contribution to the heat of polymerization from the addition of $\mathrm{H}-$ $\mathrm{OH}$ would then be very small. The explanation for the heat of polymerization is to be found in the following consideration. The three-member ring of ethylene oxide has been regarded as a strained structure [21] but Walsh [22, 23] (see also $[24,25,26,27])$ believes it advantageous to translate much of the old idea of strain in ethylene, cyclopropane, ethylene oxide, and other similar molecules into terms of hybridization. He has suggested that ethylene oxide contains overlapping orbitals and carbon atoms that are more nearly trigonal (ethylenic) than tetrahedral. When this molecule is converted to a straight-chain polymer structure containing ordinary tetrahedral $\mathrm{C}$ atoms, energy will be evolved, as with ethylene.

The effect of the esterification of the acrylic acids is confusing. In the case of acrylic acid, esterification increases the heat of polymerization, whereas the opposite effect occurs with methacrylic acid.

The heat of copolymerization of the butadienestyrene mixture lies between the values for the separate monomers. Copolymers having different monomer ratios from those given will of course have different heats of polymerization. The heats of copolymerization of vinyl acetate with maleic anhydride, diethyl maleate, and diethyl fumarate are lower than the heat of polymerization of vinyl acetate alone. In some cases, however, the effect of steric hindrance between side groups in copolymers may be diminished by $1: 1$ alternation of the units. Tong and Kenyon [28] have observed that with methyl acrylate and methyl methacrylate the heat of copolymerization is higher than the sum of the heats of polymerization of the components alone. These authors [29] point out that with the diethyl fumarate and maleate copolymers with vinyl acetate, the difference in their heats of copolymerization is less 
than half of the heat of isomerization of maleic to fumaric esters, suggesting that different stereoisomers are produced. A discussion of heat of copolymerization appears in reference [30].

Polymers having different structure, although derived from the same monomer (see butadiene [31]) may have different heats of polymerization. In a polymer or copolymer containing a diene, there is the possibility that there will be present a mixture of 1,2- and 1,4-addition (or 3,4- in isoprene), and the value of heat of polymerization will vary according to the ratio [32, 33, 34, 35]. The 1,2-addition may lead to cross-linking. The 1,4-polymers may be partly cis and partly trans structure.

Ethylene [36, 37, 38] and vinylidene chloride $[39,40]$ both form polymers that are rather highly crystalline. The polymers of ethylene oxide and acrylonitrile also are probably crystalline. The apparent heat of polymerization to solid polymer must then include a small quantity representing the heat of crystallization, depending on the percentage of crystallinity. If we use the value for heat of fusion of polyvinylidene chloride $(0.3 \mathrm{kcal})$ given by Reinhardt [39], then the heat of polymerization in the liquid states would be reduced from 14.4 [41] to $14.1 \mathrm{kcal} / \mathrm{mole}$ of monomer at $76.8^{\circ} \mathrm{C}$.

The author expresses his appreciation for helpful comments offered by Raymond F. Boyer, D. R. Stull, L. K. J. Tong and W. O. Kenyon, Ralph S. Jessup, Edward J. Prosen, and Leo A. Wall.

It has been brought to our attention that there is no reported value for the heat of polymerization of vinyl chloride. An estimate of the value can be made by considering its structure and comparing with other values in the table. Not enough data are available for an accurate prediction, but at least a rough idea can be obtained. Assuming that the end effects are negligible in all cases, and that the heats of vaporization are the same for the monomers as for their polymers, vinyl chloride should be between ethylene (19.6 $\mathrm{kcal} / \mathrm{mole}$, no end effect, gas-gas) and vinylidene chloride (at $25^{\circ}$, about $14.0 \mathrm{kcal} / \mathrm{mole}$, liquidliquid), and somewhere near propylene since the bond and steric effects of $\mathrm{Cl}$ are similar to those for $\mathrm{CH}_{3}$. To obtain an estimate from the data of Fontana and Kidder for propylene, their value may be adapted by subtracting $0.7 \mathrm{kcal}$ for heat of fusion of the polypropylene (same as for the monomer), and adding a few tenths of a kilocalorie for raising the temperature from $-75^{\circ}$ to $25^{\circ} \mathrm{C}$. The value then becomes about $16 \mathrm{kcal} /$ mole for liquid-liquid at $25^{\circ} \mathrm{C}$. The second estimate, obtained from ethylene and vinylidene chloride, should be somewhat above the midpoint of the difference between 19.6 and 14.0, since substitution of a second chlorine causes a greater steric effect than that of the first. The final estimate for vinyl chloride might then be placed at about $17 \mathrm{kcal} / \mathrm{mole}$ (liquid-liquid or gas-gas, $\left.25^{\circ} \mathrm{C}\right)$.

\section{References}

[1] P. J. Flory, J. Am. Chem. Soc. 59, 241 (1937).

[2] W. A. Roth and E. Rist-Schumacher, Kautschuk 18, 137 (1942).

[3] A. G. Evans and M. Polanyi, Nature 15\%, 738 (1943).

[4] A. G. Evans and E. Tyrrall, J. Polymer Sci. 2, 387 (1947).

[5] E. J. Prosen and F. D. Rossini, J. Research NBS 34, 59 (1945) RP1628.

[6] R. F. Boyer and R. S. Spencer, J. Applied Phys. 15, 398 (1944).

[7] E. J. Prosen and F. D. Rossini, J. Research NBS 34, 263 (1945) RP1642.

[8] E. J. Prosen and F. D. Rossini, J. Research NBS 36, 269 (1946) RP1702.

[9] Selected Values of Properties of Hydrocarbons. Table 11p (Part 1). National Bureau of Standards, Washington 25, D. C. (February 28, 1949).

[10] M. S. Kharasch, BS J. Research 2, 359 (1929) RP41.

[11] G. B. Kistiakowsky, J. R. Ruhoff, H. A. Smith, and W. E. Vaughan, J. Am. Chem. Soc. 57, 876 (1935).

[12] G. B. Kistiakowsky, J. R. Ruhoff, H. A. Smith, and W. E. Vaughan, J. Am. Chem. Soc. 58, 137 (1936).

[13] E. J. Prosen, private communication.

[14] E. J. Prosen, W. H. Johnson, and F. D. Rossini, J. Research NBS 37, 51 (1946) RP1728.

[15] R. S. Jessup, J. Chem. Phys. 16, 661 (1948).

[16] V. V. Korshak and K. K. Samplanskaya, Doklady Akad. Nauk SSSR 59, 497 (1948). (Chem. Abstracts 42, 6203 (1948)).

[17] D. E. Roberts and R. S. Jessup, 1948, to be published.

[18] H. Moureu and M. Dode, Bul. soc. chim. [5] 4, 637 (1937).

[19] P. J. Flory, J. Am. Chem. Soc. 62, 1561 (1940).

[20] S. Perry and H. Hibbert, J. Am. Chem. Soc. 62, 2599 (1940).

[21] H. de V. Robles, Recueil des Travaux Chimiques des Pays-Bas 59, 184 (1940).

[22] A. D. Walsh, Nature 159, 165 and 712 (1947).

[23] A. D. Walsh, Trans. Faraday Soc. 45, 179 (1949).

[24] T. M. Sugden, Nature 160, 367 (1947).

[25] P. Karrer, Helv. Chim. Acta. 30, 1780 (1947). 
[26] C. L. Arcus, Chem. and Ind. 1947, 646.

[27] C. A. Coulson and W. E. Moffitt, Phil. Mag. 40, 1 (1949).

[28] L. K. J. Tong and W. O. Kenyon, unpublished, private comunication.

[29] L. K. J. Tong and W. O. Kenyon, J. Am. Chem. Soc. J1, 1925 (1949).

[30] T. Alfrey, Jr., and C. Lewis, J. Polymer Sci. 4, 221 (1949).

[31] S. V. Lebedev, G. G. Koblyanskiř, M. A. Khokhlovkin, N. I. Kurbina, and M. M. Gol'dman, Trudy Gosudarst. Opyt. Zavoda Sintet. Kauchuka Litera B. IV. Synthetic Rubber 1935, 46. (Chem. Abstracts 31, 6958 (1937)).

[32] A. Saffer and B. L. Johnson, Ind. Eng. Chem. 40, 538 (1948).

[33] H. L. Dinsmore and D. C. Smith, Anal. Chem. 20, 11 (1948).

[34] A. W. Meyer, Ind. Eng. Chem. 41, 1570 (1949). See also E. J Hart and A. W. Meyer, J. Am. Chem. Soc. 71, 1980 (1949).

[35] I. M. Kolthoff, T. S. Lee, and M. A. Mairs, J. Polymer Sci. 2, 220 (1947).

[36] E. Hunter and W. G. Oakes, Trans. Faraday Soc. 41, 49 (1945).

[37] H. C. Raine, R. B. Richards, and H. Ryder, Trans. Faraday Soc. 41, 56 (1945).

[38] G. S. Parks and J. R. Mosley, J. Chem. Phys. 17, 691 (1949).

[39] R. C. Reinhardt, Ind. Eng. Chem. 35, 422 (1943).

[40] W. C. Goggin and R. D. Lowry, Ind. Eng. Chem. 34, 327 (1942).

[41] L. K. J. Tong and W. O. Kenyon, J. Am. Chem. Soc. 69, 2245 (1947).

[42] C. M. Fontana and G. A. Kidder, J. Am. Chem. Soc. \%0, 3745 (1948).

[43] R. M. Thomas, W. J. Sparks, P. K. Frolich, M. Otto, and M. Mueller-Cunradi, J. Am. Chem. Soc. 62, 276 (1940)

[44] B. A. Kazanskiǐ and M. I. Rozengart, J. Gen. Chem. (USSR) 12, 246 (1942). (Chem. Abstracts 3\%, 3045) (1943)).
[45] W. von Luschinsky, Z. physik. Chem. A182, 384 (1938).

[46] A. Votinov, P. Kobeko, and F. Marě̌, J. Phys. Chem. (USSR) 16, 106 (1942). Chem. Abstracts 37, 5304 (1943).

[47] G. Goldfinger, D. Josefowitz, and H. Mark, J. Am. Chem. Soc. 65, 1432 (1943).

[48] W. J. Ferguson, I. C. Schoonover, and F. G. Brickwedde, National Bureau of Standards 1945, unpublished.

[49] L. K. J. Tong and W. O. Kenyon, J. Am. Chem. Soc. 69, 1402 (1947).

[50] D. E. Roberts, W. W. Walton, and R. S. Jessup, J. Research NBS, 38, 627 (1947) RP1801. Also J. Polymer Sci. 2, 420 (1947).

[51] H. Staudinger and P. Schläpfer, unpublished data, quoted in chapter by G. V. Schulz in Chemie und Technologie der Kunststoffe, edited by R. Houwink, Vol. 1, p. 60, Table 5, Leipzig, (1942); or (one vol.) p. 79, Table 6, Leipzig (1939).

[52] M. F. Shostakovskil and I. F. Bogdanov, J. Applied Chem. (USSR) 15, 249 (1942). (Chem. Abstracts 37, $2486(1943))$.

[53] S. Iwai, J. Soc. Chem. Ind. (Japan) 49, 185 (1946). (Chem. Abstracts 42, 6161 (1948)).

[54] L. K. J. Tong and W. O. Keynon, J. Am. Chem. Soc. 6\%, 1278 (1945).

[55] L. K. J. Tong and W. O. Kenyon, J. Am. Chem. Soc. 68, 1355 (1946).

[56 E. Kunst and M. Magat, Compt. rend. 225, 499 (1947).

[57] D. E. Roberts and R. S. Jessup, 1948, to be published.

[58] E. Baur and S. Frater, Helv. Chim. Acta. 24, 768 (1941).

[59] R. S. Jessup, J. Research, NBS 20, 589 (1938) RP1093.

[60] R. S. Jessup, Preliminary Report, 1944, unpublished.

[61] D. E. Roberts, R. S. Jessup, 1944, unpublished.

[62] J. E. Kilpatrick, C. W. Beckett, E. J. Prosen, K. S. Pitzer, and F. D. Rossini, J. Research NBS 42, 225 (1949) RP1964.

Washington, October 6, 1949. 